\title{
IMPLEMENTASI SISTEM MANAJEMEN K3 PADA PROYEK PEMBANGUNAN GKB UNIVERSITAS NEGERI MALANG
}

\author{
Lenny Novitasari \\ Suparno dan Boedi Rahardjo
}

\begin{abstract}
Abstrak:Kesehatan dan keselamatan kerja (K3) sangat penting untuk mencegah dan mengurangi kecelakaan dan penyakit akibat kerja serta terciptanya tempat kerja yang aman, efisien dan produktif. Hasil penelitian menunjukkan: 1) Komitmen dan kebijakan dalam proyek dibuat langsung dengan berdasarkan standart perusahaan. 2) Perencanaan K3 dilakukan proyek konstruksi GKB UM dengan mengidentifikasi bahaya, melakukan penilaian risiko, dan menentukan pengendalian risiko. Kemudian perencanaan K3 diawali dengan membuat safety plan yang disusun berdasarkan penilaian awal dan juga berdasarkan undang-undang dan persyaratan K3 terkait. 3) Proyek konstruksi para pekerja dan karyawan baru akan diberikan safety induction dan cek kesehatan. APD disediakan secara lengkap sesuai potensi risiko dan setiap pekerja diwajibkan untuk menggunakan APD selama bekerja dilapangan, melaksanakan she talk dan toolbox meeting secara rutin sebagai bentuk komunikasi K3 antar pekerja. 4) Pemantauan dan evaluasi K3 dilakukan dengan kegiatan inspeksi secara berkala untuk memastikan bahwa setiap potensi bahaya yang dapat timbul dari kondisi tempat kerja, peralatan kerja, material serta tindakan pekerja teridentifikasi, dan juga berguna untuk mengambil tindakan perbaikan serta pencegahan yang diperlukan serta menyediakan peralatan darurat sesuai dengan peraturan tentang peralatan dan sistem tanda bahaya keadaan darurat yang disediakan, diperiksa, diuji dan dipelihara secara berkala. 5) Peninjauan dan peningkatan dilaksanakan dengan membuat statistik risiko kecelakaan maupun audit temuan yang terjadi di proyek serta melakukan perbaikan terhadap penyimpangan yang ditemukan.
\end{abstract}

Kata-kata kunci: GKB, Implementasi, Sistem Manajemen K3

\begin{abstract}
Occupational health and safety $(K 3)$ is very important to prevent and reduce occupational accidents and diseases as well as the creation of a safe, efficient and productive workplace. The results showed: 1) Commitments and policies in the project were made directly based on company standards. 2) OHS planning is carried out by the UM GKB construction project by identifying hazards, conducting risk assessments, and determining risk control. Then OHS planning begins with making a safety plan based on initial assessments and also based on laws and related OSH requirements. 3) Construction project workers and new employees will be given safety induction and health checks. PPE is provided in full according to potential risks and every worker is required to wear PPE while working in the field, carry out she talk and toolbox meetings regularly as a form of $K 3$ communication between workers. 4) OHS monitoring and evaluation are carried out with periodic inspection activities to ensure that any potential hazards that may arise from workplace conditions, work equipment, materials and worker actions are identified, and are also useful for taking necessary corrective and preventive actions and providing emergency equipment. in accordance with the regulations regarding the equipment and system of emergency alerts provided, checked, tested and maintained periodically. 5) Reviews and improvements are carried out by making accident risk statistics and auditing the findings that occur in the project and making corrections to any deviations found.
\end{abstract}

Keywords: GKB, Implementation, K3 Management System

Lenny Novitasari adalah Alumni Jurusan Teknik Sipil Fakultas, Email: nlenny85@gmail.com; Suparno dan Boedi Rahardjo adalah Dosen Jurusan Teknik Sipil Fakultas Teknik UM; Jalan Semarang No.5 Malang 65145; Email: parno.malang@gmail.com, boedi.rahardjo.ft.um.ac.id 


\section{PENDAHULUAN}

Proyek konstruksi merupakan suatu rangkaian kegiatan dalam suatu lingkup tertentu yang mempunyai dimensi waktu, fisik dan biaya guna mewujudkan gagasan serta mendapatkan tujuan yang diinginkan, seperti fasilitas, biaya yang ekonomis, metode konstruksi beserta cara untuk pelaksanaan suatu proyek konstruksi (Prayetti dkk, 2017). Industri konstruksi memiliki sifat tipe yang berbeda pada setiap proyeknya antara lain metode pelaksanaan, karakter proyek, material yang digunakan hingga teknik pengaplikasian yang berbeda, untuk itu industri konstruksi memiliki tingkat resiko kecelakaan kerja yang relatif tinggi (Yoon dkk, 2013). Menurut Kaligis (2013) pelaksanaan proyek konstruksi sangatlah rawan terhadap risiko kecelakaan kerja maupun penyakit akibat kerja. Area kerja yang terbuka, pengaruh cuaca serta lingkungan kerja yang padat alat dan juga material membuat risiko-risiko kecelakaan tidak dapat dihindari. Untuk mencegah kerugian dari proyek konstruksi, diperlukan suatu sistem manajemen K3 yang mengatur dan menjadi acuan bagi konsultan, kontraktor dan para pekerja konstruksi (Sihombing dkk, 2014).

Keselamatan dan kesehatan kerja merupakan hal yang penting bagi perusahaan, karena dampak kecelakaan dan penyakit kerja tidak hanya merugikan karyawan, tetapi juga perusahaan baik secara langsung maupun tidak langsung (Sepang dkk, 2013). Implementasi K3 merupakan upaya untuk mencapai hasil atau tujuan yang telah ditetapkan melalui kegiatan perencanaan, pengorganisasian, kepemimpinan dan pengendalian, selain itu juga kemampuan untuk mengelola semua hal secara profesional. Kesehatan dan keselamatan kerja (K3) sangat penting sebagai upaya untuk mencegah dan mengurangi kecelakaan dan penyakit akibat kerja serta terciptanya tempat kerja yang aman, efisien dan produktif (Tjakra dkk, 2013). Secara umum faktor penyebab kecelakaan kerja disebabkan oleh faktor manusia (unsafe acts), yaitu berupa tindakan manusia yang tidak mematuhi prosedur yang telah ditetapkan, selain faktor manusia juga disebabkan oleh faktor lingkungan (unsafe condition) yaitu keadaan lingkungan kerja yang tidak aman seperti penerangan yang minim, cuaca, kebisingan dan lantai kerja yang licin (Waruwu dan Yuamita, 2016).

Sebagai contoh kecelakaan kerja yang terjadi baru-baru ini adalah jatuhnya 2 pekerja yang sedang melaksanakan pekerjaan bekisting pada proyek pembangunan Mal Boxies 123 Tajur di Kota Bogor (Sindonews, 16 Januari 2019) dan kecelakaan kerja akibat pekerja terjatuh dari lantai 5 yang menyebabkan korban jiwa sebanyak 3 orang dan 3 orang luka berat pada proyek pembangunan Hotel Raja di Kota Semarang (Sindonews, 1 November 2018). Pada tahun 2014 kecelakaan kerja terjadi pada proyek pembangunan gedung LKPP Jakarta Selatan, kecelakaan terjadi karena lengan konstruksi tower crane jatuh menimpa pekerja ketika sedang dibongkar sehingga menyebabkan 2 pekerja luka dan 1 pekerja tewas (Merdeka.com, 1 Oktober 2014).

GKB merupakan bangunan infrastruktur yang menjadi salah satu upaya UM untuk melaksanakan mandat Kemenristekdikti menjadi pusat unggulan iptek bidang inovasi pem- 
belajaran atau center of excellence in learning innovation. Proyek ini direncanakan akan dibangun twin tower atau dua gedung kembar 9 lantai yang saling berhadapan, dengan amphiteater yang ditempatkan ditengah tengah dua gedung tersebut sebagai sarana penunjang pembelajaran serta dilengkapi gardu listrik dan genset. Proyek konstruksi GKB UM memiliki luas lahan $\pm 39.640 \mathrm{~m} 2$ dan luas bangunan sekitar $\pm 44.917 \mathrm{~m} 2$ serta rencana durasi penyelesaian gedung adalah 22 bulan dimulai dari akhir bulan Agustus 2018 hingga bulan Juni 2020. Pembangunan dimulai dari pekerjaan persiapan, pekerjaan tanah, pekerjaan pondasi, pekerjaan beton bertulang, pekerjaan dinding, pekerjaan atap dilanjutkan sampai pekerjaan finishing yang tergolong pada pekerjaan dalam ruang terbuka (open space).

Menurut Pangkey (2012) bekerja dalam ruang terbuka memiliki risiko terjadinya kecelakaan kerja yang cukup tinggi dengan dipengaruhi oleh perubahan cuaca, jangka waktu pekerjaan yang terbatas, menggunakan peralatan kerja yang membahayakan keselamatan dan kesehatan kerja serta melakukan pekerjaan yang banyak mengeluarkan tenaga. Proyek konstruksi GKB mempunyai tingkat kompleksitas tinggi yang terdiri dari beragam material yang digunakan pada proyek, peralatan penunjang pembangunan seperti alat berat yang membutuhkan dana cukup besar untuk pengoperasiannya, jumlah tenaga kerja yang mencapai 382 orang/hari dari banyak bidang mulai dari tukang sampai engineer, banyaknya pihak yang terkait dalam perijinan pembangunan proyek, dan dana yang digunakan.

Berdasarkan latar belakang diatas dapat mendeskripsikan bentuk SMK3 pada proyek GKB UM yang meliputi penetapan komitmen dankebijakanK3,perencanaanK3, pelaksanaan dan penerapan K3, pemantauan dan evaluasi K3 serta peninjauan dan peningkatan kinerja K3

\section{METODE}

\section{Rancangan Penelitian}

Penelitian ini dilakukan dengan menggunakan pendekatan kualitatif metode deskriptif dengan cara mendiskripsikan kesesuaian masing-masing pedoman sistem manajemen K3 dari penetapan kebijakan $\mathrm{K} 3$, perencanaan $\mathrm{K} 3$, pelaksanaan penerapan K3, pemantauan dan evaluasi kinerja $\mathrm{K} 3$, peninjauan dan peningkatan kinerja $\mathrm{K} 3$.

\section{Data Penelitian}

Sumber data dalam penelitian ini menggunakan dua sumber yaitu sumber data primer dan sumber data sekunder. Sumber data primer pada penelitian ini diperoleh dari pendapat subyek penelitian secara langsung melalui kegiatan wawancara. Sedangkan sumber data sekunder merupakan yang diperoleh dari bahan pustaka, artikel, jurnal, dokumentasi, data internal perusahaan maupun dokumen penunjang lainnya. Sumber data utama dalam penelitian kualitatif ialah kata-kata dan tindakan selebihnya adalah data tambahan seperti dokumen dan lain-lain. Penelitian ini menggunakan pendekatan kualitatif, maka peneliti menggunakan metode wawancara dan dokumentasi dalam pengumpulan data primer. Adapun peneliti membagi sumber data dalam penelitian ini sebagai berikut: 1. Informan, yaitu orang yang mem- 
beri informasi tentang data yang diinginkan oleh peneliti berkaitan dengan penelitian yang sedang dilakukan. 2. Dokumen, yaitu teknik dokumentasi yang digunakan untuk memperoleh data melalui data tertulis. Teknik ini dilakukan untuk melengkapi informasi peneliti dan untuk mendapatkan data yang akurat. 3. Sumber data sekunder, dalam penelitan ini meliputi dokumen yang dapat digunakan sebagai penunjang, seperti buku dan jurnal. Dalam penelitian ini peneliti sendiri yang menjadi instrumen utama penelitian. Selain itu terdapat instrumen tambahan yang digunakan dalam penelitian ini yaitu pedoman wawancara, catatan lapangan dan instrumen penunjang yaitu kamera dan alat perekam suara.

\section{Analisis Data Penelitian}

Model analisis yang digunakan dalam penelitian ini adalah analisis model Spreadly yang terdiri dari empat tahap dalam analisis data pada penelitian kualitatif, yaitu analisis domain, analisis taksonomi, analisis komponen dan analisis tema.

\section{Pemeriksaan Keabsahan Data}

Pemeriksaan keabsahan data pada penelitian ini menggunakan metode triangulasi sumber yaitu dengan cara berikut: 1. Membandingkan data hasil pengamatan dengan hasil wawancara,

2. Membandingkan apa yang dikatakan orang didepan umum dengan apa yang dikatakan secara pribadi,

3. Membandingkan apa yang dikatakan orangorang tentang situasi penelitian dengan apa yang dikatakannya sepanjang waktu,

4. Membandingkan keadaan dan prespektif seseorang dengan berbagai pendapat dan pandangan orang,

5. Membandingkan hasil wawancara dengan isi suatu dokumen yang berkaitan.

\section{HASIL DAN PEMBAHASAN}

Berdasarkan penelitian yang telah dilakukan berikut hasil penelitian terkait implementasi sistem manajemen K3 yang meliputi penetapan komitmen, perencanaan, penerapan pemantauan dan peningkatan:

(1) Komitmen dan kebijakan dalam proyek dibuat langsung dengan berdasarkan standart perusahaan. Komitmen K3 didokumentasikan dan dikomunikasikandengan ditempatkan pada bagian depan proyek sejajar dengan pintu masuk proyek sehingga dapat dibaca oleh semua pihak. Tim proyek GKB UM memiliki komitmen dan kebijakan yang sangat baik dalam menjamin terlaksanana sistem manajemen. Hal tersebut terbukti dengan adanya organisasi P2K3L yang merupakan organsasi tanggap darurat sebagai bentuk koordinasi antara pihak manajemen dan lapangan dalam menerapkan K3. Selain itu terdapat kebijakan perusahaan, stop working authority, drug and alcohol policy serta kebijakan proyek yang diterapkan dalam lingkungan proyek. Kebijakan tersebut dikomunikasikan dalam bentuk induction dan dalam bentuk hardcopy pada papan informasi.

(2) Perencanaan K3 proyek dilakukan penyelenggara proyek GKB UM tergolong baik. Hal tersebut ditunjukkan dengan menyusun IBPR di tempat kerja untuk menentukan upaya dalam pengendalian risiko yang kemudian digunak- 
an sebagai acuan untuk menyusun safety plan.

(3) Pada proyek konstruksi GKB UM semua pekerja dan karyawan baru akan diberikan safety induction untuk memberikan pelatihan dan pengetahuan tentang pentingnya menjaga keselamatan dan kesehatan kerja pada lingkungan kerja, kemudian pekerja dan karyawan baru akan dilakukan cek kesehatan untuk mengetahui tingkat kesehatan atau penyakit yang diderita pekerja ataupun karyawan. Selain melakukan safety induction dan cek kesehatan, proyek GKB UM juga menyediakan APD secara lengkap dan setiap pekerja diwajibkan untuk menggunakan APD selama bekerja dilapangan, melakukan pekerjaan sesuai prosedur serta mengetahui jenis bahaya kecelakaan kerja. Hal tersebut merupakan tanggung jawab semua pekerja terhadap keselamatan dan kesehatan kerja. Proyek GKB UM juga melaksanakan she talk dan toolbox meeting secara rutin sebagai bentuk komunikasi K3 antar pekerja.

(4) Tim SHE melakukan penilaian kesesuaian dan kepatuhan terhadap undang-undang yang disebut dengan safety assesment atau QSHE assesment yang akan dilaporkan secara online melalui website perusahaan. (5) Peninjauan dan peningkatan dilaksanakan bertujuan untuk melakukan perbaikan terhadap penyimpangan yang ditemukan. Perbaikan dilakukan sebagai masukan dalam meningkatkan.

Berdasarkan hasil penelitian, berikut pembahasan terkait implementasi sistem manajemen K3 pada proyek GKB UM yang meliputi penetapan komitmen dan kebijakan, perencanaan, penerapan, pemantauan dan peningkatan:

1.Penetapan Komitmen dan Kebijakan
Komitmen dan kebijakan K3 merupakan salah satu pedoman dalam sistem manajemen keselamatan dan kesehatan kerja proyek konstruksi GKB UM. Komitmen dan kebijakan dalam proyek dibuat langsung dengan berdasarkan standart perusahaan. Komitmen K3 didokumentasikan dan dikomunikasikan dengan ditempatkan pada bagian depan proyek sejajar dengan pintu masuk proyek sehingga dapat dibaca oleh semua pihak. Tim proyek GKB UM memiliki komitmen dan kebijakan yang sangat baik dalam menjamin terlaksanana sistem manajemen. Hal tersebut terbukti dengan adanya organisasi P2K3L yang merupakan organsasi tanggap darurat sebagai bentuk koordinasi antara pihak manajemen dan lapangan dalam menerapkan K3. Selain itu terdapat kebijakan perusahaan, stop working authority, drug and alcohol policy serta kebijakan proyek yang diterapkan dalam lingkungan proyek.

Kebijakan tersebut dikomunikasikan dalam bentuk induction dan dalam bentuk hardcopy pada papan informasi. Penerapan SMK3 berguna untuk menciptakan lingkungan kerja yang aman, nyaman dan sehat sehingga pekerja terhindar dari kecelakaan dan penyakit akibat kerja. Hal ini sesuai dengan SMK3 PP No. 50 tahun 2012 yang menyatakan bahwa komitmen dan kebijakan K3 merupakan perwujudan komitmen perusahaan yang memuat visi, tujuan perusahaan, komitmen dan tekad melaksanakan kebijakan, kerangka dan program kerja yang mecakup kegiatan perusahaan secara menyeluruh yang bersifat umum dan operasional. Pangkey,dkk (2012) komitmen dan kebijakan baik apabila terdapat pengendalian setiap risiko mutu, 
keselamatan dan kesehatan lingkungan.

2.Perencanaan, Selain komitmen dan kebijakan K3, perencanaan K3 juga merupakan salah satu pedoman manajemen keselamatan dan kesehatan kerja proyek konstruksi GKB UM. Perencanaan K3 proyek dilakukan penyelenggara proyek GKB UM tergolong baik. Hal tersebut ditunjukkan dengan menyusun identifikasi sumber bahaya, pengendalian dan penialian risiko di tempat kerja untuk menentukan upaya dalam pengendalian risiko yang kemudian digunakan sebagai acuan untuk menyusun safety plan.

Berdasarkan hasil penelitian proses perencanaan K3 yang telah dilakukan proyek konstruksi GKB UM sudah terbilang baik, yaitu dengan mengidentifikasi bahaya, melakukan penilaian risiko, dan menentukan pengendalian risiko. Kemudian perencanaan K3 diawali dengan membuat safety plan yang disusun berdasarkan penialaian awal dan juga berdasarkan undang-undang dan persyaratan K3 terkait. Sepaham dengan penelitian Pangkey, dkk (2012) perencanaan K3 baik apabila telah dilakukan identifikasi bahaya, penilaian dan pengendalian.

3.Penerapan, Berdasarkan hasil penelitian diketahui bahwa proyek konstruksi GKB UM sudah melaksanakan sistem manajemen K3 berdasarkan peraturan dari perusahaan yang mengacu pada PP No.50 tahun 2012 maupun pada OHSAS 18001:2007. SDM yang disediakan harus menyerahkan surat izin kerja kemudian diberi tanggung jawab dan wewenang untuk menjalankan, memelihara dan meningkatkan tingkat keselamatan dan kesehatan kerja dalam lingkungan kerja. Pada proyek konstruksi GKB UM semua pekerja dan karyawan baru akan diberikan safety induction untuk memberikan pelatihan dan pengetahuan tentang pentingnya menjaga keselamatan dan kesehatan kerja pada lingkungan kerja, kemudian pekerja dan karyawan baru akan dilakukan cek kesehatan untuk mengetahui tingkat kesehatan atau penyakit yang diderita pekerja ataupun karyawan. Selain melakukan safety induction dan cek kesehatan, proyek GKB UM juga menyediakan APD secara lengkap dan setiap pekerja diwajibkan untuk menggunakan APD selama bekerja dilapangan, melakukan pekerjaan sesuai prosedur serta mengetahui jenis bahaya kecelakaan kerja. Hal tersebut merupakan tanggung jawab semua pekerja terhadap keselamatan dan kesehatan kerja. Proyek GKB UM juga melaksanakan she talk dan toolbox meeting secara rutin sebagai bentuk komunikasi K3 antar pekerja. Orilian,dkk. (2018) pelaksanaan rencana K3 tergolong baik apabila safety talk dilakukan sesuai dengan jadwal, oknum yang tidak menggunakan APD secara lengkap saat bekerja akan mendapatkan teguran dan peringatan.

4.Pemantauan, Dari hasil penelitian, pemantauan dan evaluasi K3 sudah sesuai dengan PP No.50 tahun 2012 dan juga OHSAS 18001:2007, dimana perusahaan telah melaksanakan pemantauan dan evaluasi secara rutin. Tim SHE melakukan penilaian kesesuaian dan kepatuhan terhadap undang-undang yang disebut dengan safety assesment atau QSHE assesment yang akan dilaporkan secara online melalui website perusahaan. Hal ini sesuai dengan PP No.50 tahun 2012 yang menyatakan bahwa hasil pemantauan dan evaluasi K3 
dilaporkan kepada perusahaan. Tim audit melakukan inspeksi secara berkala yang bertujuan untuk memastikan bahwa setiap potensi bahaya yang dapat timbul dari kondisi tempat kerja, peralatan kerja, material serta tindakan pekerja teridentifikasi, dan juga berguna untuk mengambil tindakan perbaikan serta pencegahan yang diperlukan untuk mencegah terjadinya kecelakaan kerja dari potensi bahaya tersebut. Ketika terjadi kecelakaan kerja tim akan langsung melakukan penyelidikan untuk mengidentifikasi kejadian, mencari ketidaksesuaian, dan menentukan upaya pencegahan. Penyelidikan insiden kecelakaan dilaksanakan sesegera mungkin agar dapat ditentukan tindakan koreksi serta tindakan pencegahan. Perusahaan juga melaksanakan audit internal secara berkala yang dilakukan oleh tim dari pusat serta audit eksternal. Hasil temuan penelitian ini menyebutkan bahwa ada upaya untuk menghadapi situasi darurat dengan dibentuknya struktur organsasi tim tanggap darurat. Tim ini diberikan pelatihan dan simulasi agar setiap anggota mengetahui peran serta tanggung jawab masing-masing, hal ini relevan dengan penelitian Ramli (2010) menyatakan bahwa penanggulangan keadaan darurat tidak akan berhasil jika tidak ditangani oleh petugas atau SDM yang berkompeten dengan melakukan upaya pembinaan dan pelatihan yang terencana dan berkesinambungan dikemas dalam bentuk permainan peran atau uji coba dalam kondisi berbagai bentuk skenario sehingga mengetahui peran dan tanggung jawabnya masing-masing.

Selain pembentukan tim tanggap darurat, perusahaan juga menyediakan pera- latan darurat sesuai dengan peraturan tentang peralatan dan sistem tanda bahaya keadaan darurat yang disediakan, diperiksa, diuji dan dipelihara secara berkala. Adapun peralatan dan sistem tanda bahaya yang terdapat di proyek GKB UM antara lain :

a.APAR (Alat Pemadam Api Ringan), dil etakkan di berbagai tempat yang mudah dijangkau. Dari hasil check list APAR diketahui bahwa sudah dilakukan pemerikasaan APAR secara rutin yaitu setiap bulan dan menunjukkan bahwa kondisi APAR yang tersedia dalam kondisi baik.

b.Kotak P3K, diletakkan di berbagai tem pat yang mudah dijangkau. Dari hasil check list kotak P3K secara rutin yaitu setiap bulan dan menunjukkan bahwa kondisi kotak dan obat-obatan yang tersedia dalam kondisi baik dan lengkap.

c.Layout, Petunjuk/rambu dan titik evakua si, di pasang di tempat yang mudah dilihat. Sepaham dengan penelitian yang dilakukan Mentang,dkk (2013) pemantauan dan evaluasi baik apabila telah melakukan penilaian efetivitas SMK3 melalui audit dan inspeksi K3 dengan mengevaluasi semua bahaya kecelakaan baik dari pekerja, peralatan kerja dan lingkungan pada penerapan SMK3.

5.Peningkatan, Berdasarkan hasil penelitian diketahui bahwa peninjauan dan peningkatan dilaksanakan bertujuan untuk melakukan perbaikan terhadap penyimpangan yang ditemukan. Perbaikan dilakukan sebagai masukan dalam meningkatkan program K3 kedepannya untuk upaya peningkatan kinerja di perusahaan. Hal ini sesuai dengan PP No.50 tahun 2012 yang menyatakan bahwa perusa- 
46 JURNAL BANGUNAN, VOL. 25, NO.2, OKTOBER 2020: 39-48

haan wajib melakukan peninjauan sebagai upaya perbaikan dan peningkatan kinerja. Hal ini juga sesuai dengan OHSAS yang menyatakan bahwa tinjauan ulang ulang SMK3 harus dapat mengatasi implikasi K3 terhadap seluruh kegiatan, produk barang dan jasa termasuk dampaknya terhadap kinerja perusahaan.

\section{SIMPULAN}

Berdasarkan hasil penelitian dan pembahasan yang telah dijelaskan, maka diperoleh kesimpulan bahwa : (1) Penetapan komitmen dan kebijakan keselamatan dan kesehatan kerja ditetapkan oleh kantor pusat yaitu PT. PP (Persero), (2) Perencanaan K3 dilaksanakan berdasarkan hasil tinjauan awal kondisi K3 seperti data IBPR serta perssyaratan hukun undang-undang perencanaan K3, (3) Pelaksanaan K3 terdapat tim K3 terpilih yang memiliki peran dan tanggung jawab, pelaksanaan pelatihan secara berkala serta melakukan komunikasi K3 secara rutin, (4) Pemantauan dan evaluasi kinerja K3 dilakukan dengan melaksanakan kegiatan monitoring setiap bulan dan juga setiap minggu. Melakukan penyelidikan insiden sebagai langkah pencegahan, dan internal audit, (5) Peninjauan dan peningkatan SMK3 dilakukan dengan melaksanakan pelaporan hasil temuan kemudian melakukan rapat manajemen sebagai upaya peningkatan performa dan kinerja K3.

\section{DAFTAR RUJUKAN}

Kaligis, R.S.V., Sompie, B.F., Tjakra, J.,\& Walangitan, D.R.O. (2013). Pengaruh Im plementasi Program Keselamatan dan Kes ehatan Kerja (K3) Terhadap Produktifitas Kerja. Jurnal Sipil Statik Vol. 1/No. 3/ Feb ruari 2013. (Online) (ejournal.unsrat.ac.id), diakses 5 Agustus 2019.

Merdeka, 2014. Kecelakaan kerja di proyek gedung LKPP satu tewas. (merdeka.com).

Pangkey, F., Malingkas, G.Y.,\& Walangitan, D.O.R. 2012 . Penerapan Sistem Mana jemen Keselamatan dan Kesehatan Kerja (SMK3) pada Proyek Konstruksi di Indo nesia (Studi Kasus Pembangunan Jembatan Dr. Ir. Soekarno-Manado). Jurnal Ilmiah MEDIA ENGINEERING Vol. 2/No. 2/Juli 2012 ISSN : 2087-9334. (Online) (ejour nal.unsrat.ac.id), diakses 3 Agustus 2019. Prayetti, M.D., Rafie.,\& Pratiwi, R. 2017. Ren cana Keselamatan dan Kesehatan Kerja (K3) Kontrak pada Pembangunan Gedung Sekolah Dasar Immanuel Pontianak. Jurnal Mahasiswa Teknik Sipil Universitas Tan jungpura Vol. 4/ No.4/ Februari 2017. (On line), (jurnal.untan.ac.id), diakses 5 Agus tus 2019.

Sepang, B.A.W., Tjakra, J., Langi, J.E.Ch.,\& Walangitan, D.O.R. 2013. Manajemen Risiko Keselamatan dan Kesehatan Kerja (K3) pada Proyek Pembangunan Ruko Or lens Fashion Manado. Jurnal Sipil Statistik Vol. 1/ No. 4/Maret 2013 ISSN : 23376732. (Online), (ejournal.unsrat.ac.id), diakses 3 Agustus 2019.

Sihombing, D., Walangitan, D.R.O.,\& Prasta sis, P.A.K. 2014. Implementasi Kesela matan dan Kesehatan Kerja (K3) pada Proyek di Kota Bitung (Studi Kasus Proyek Pembangunan Pabrik Minyak PT. MNS). Jurnal Sipil Statistik Vol. 2/No. 3/ Maret 
2014 ISSN : 2337-6732. (Online), (ejour nal.unsrat.ac.id), diakses 3 Agustus 2019. Sindonews, 2018. Angka Kecelakaan Kerja di Jatim 21631 kasus. (daerah.sindonews. com).

Sindonews, 2018. Jatuh dari lantai 5 tiga pe kerja konstruksi tewas. (daerah.sindonews. com).

Waruwu, S., \& Yuamita, F. 2016. Analisis Fak tor Kesehatan dan Keselamatan Kerja (K3) yang Signifikan Mempengaruhi Ke celakaan Kerja pada Proyek Pembangunan Apartement Student Castle. Jurnal Rekaya sa Spectrum Industri Vol. 14/No. 1/ 2016 ISSN: 2442-2630. (Online), (ejournal.uad. ac.id), diakses 10 Agustus 2019.

Yoon, Seok J., Lin, Hsing K., Chen, Gang., dkk. 2013. Effect of Occupational Health and Safety Management System of WorkRelated Accident Rate Awareness Between Managers in South Korea's Construction Industry. Elseiver: Occupational Safety and Health Research Institute. 201-209. (on line), (sciencedirect.com). diakses tanggal 15 Agustus 2019. 
48 JURNAL BANGUNAN, VOL. 25, NO.2, OKTOBER 2020: 39-48 